\title{
Modulatory effects of heparin and short-length oligosaccharides of heparin on the metastasis and growth of LMD MDA-MB 231
} breast cancer cells in vivo

\author{
P Mellor', JR Harvey', KJ Murphy², D Pye', G O'Boyle', TWJ Lennard', JA Kirby*,I and S Ali' \\ 'Breast Cancer Research Group, School of Surgical and Reproductive Sciences, Newcastle University, Newcastle-upon-Tyne, NE2 4HH, UK; ${ }^{2}$ Department \\ of Chemical and Biological Sciences, University of Huddersfield, Huddersfield, HDI 3DH, UK
}

Expression of the chemokine receptor CXCR4 allows breast cancer cells to migrate towards specific metastatic target sites which constitutively express CXCLI2. In this study, we determined whether this interaction could be disrupted using short-chain length heparin oligosaccharides. Radioligand competition binding assays were performed using a range of heparin oligosaccharides to compete with polymeric heparin or heparan sulphate binding to ${ }^{125} \mathrm{CXCL}$ 12. Heparin dodecasaccharides were found to be the minimal chain length required to efficiently bind CXCLI 2 (7I\% inhibition; $P<0.00$ I). These oligosaccharides also significantly inhibited CXCL I2-induced migration of CXCR4-expressing LMD MDA-MB 23I breast cancer cells. In addition, heparin dodecasaccharides were found to have less anticoagulant activity than either a smaller quantity of polymeric heparin or a similar amount of the low molecular weight heparin pharmaceutical product, Tinzaparin. When given subcutaneously in a SCID mouse model of human breast cancer, heparin dodecasaccharides had no effect on the number of lung metastases, but did however inhibit $(P<0.05)$ tumour growth (lesion area) compared to control groups. In contrast, polymeric heparin significantly inhibited both the number $(P<0.00 \mathrm{I})$ and area of metastases, suggesting a differing mechanism for the action of polymeric and heparin-derived oligosaccharides in the inhibition of tumour growth and metastases.

British Journal of Cancer (2007) 97, 76 I-768. doi:I0.1038/sj.bjc.6603928 www.bjcancer.com

Published online 28 August 2007

(c) 2007 Cancer Research UK

Keywords: CXCLI2; CXCR4; glycosaminoglycan; metastasis; breast cancer

Breast cancer is the most common malignancy in women and a major cause of morbidity and mortality in many parts of the world. The main cause of these deaths is metastatic spread of the disease (Dowsland et al, 2003). Breast cancer cells metastasise to specific anatomical sites, which include the brain, liver, lung and regional lymph nodes (Woodhouse et al, 1997). It appears that the metastatic spread of breast cancer cells to specific organs is dependant on the ability of these organs to express factor(s) that mediate specific cancer cell extravasation and recruitment from the blood, across the vascular endothelium and into the subendothelial tissue compartment. This process has clear parallels with the normal mechanism of leukocyte trafficking which is driven by chemokines (Muller et al, 2001).

Chemokines are small structurally related chemo-attractant cytokines that exert their effects locally in a paracrine or autocrine manner. Chemokines signal through G-protein-coupled receptors on cells inducing cytoskeletal rearrangement, firm adhesion to endothelial cells and directional migration (Zlotnik and Yoshie, 2000). These secreted proteins act in a co-ordinated fashion with cell-surface proteins, including integrins, to direct specific homing

*Correspondence: Professor JA Kirby, School of Surgical and Reproductive Sciences, 3rd Floor William Leech Building, Framlington Place, University of Newcastle, Newcastle-upon-Tyne NE2 4HH, UK.

E-mail: J.A.Kirby@ncl.ac.uk

Received 8 May 2007; revised II July 2007; accepted 13 July 2007; published online 28 August 2007 of various subsets of haematopoietic cells to specific anatomical sites (Moser et al, 2004).

There is increasing evidence that cancer cells express both chemokines and their receptors allowing both autocrine and paracrine responses, leading to migration, enhanced proliferation and cell survival (Azenshtein et al, 2002; Chen et al, 2006; Zlotnik, 2006). Indeed, metastatic breast cancer cells have been shown to express high levels of the chemokine receptor CXCR4 (Moore, 2001). In addition, organs commonly associated with being sites of breast cancer metastasis, such as lung, liver, lymph node, brain and bone, constitutively express the sole ligand for CXCR4, CXCL12 (Muller et al, 2001). Until recently, the interaction between CXCL12 and CXCR4 appeared to be unique and non-promiscuous. However, it has recently been argued that CXCL12 can interact with an additional receptor RDC1 (CXCR7), which is not thought to be involved in migration (Balabanian et al, 2005). Importantly, when signalling through CXCR4, CXCL12 stimulates intracellular calcium-flux and chemotaxis in lymphocytes, leukocytes and a range of cancer cells including breast (Amara et al, 1999; Fernandis et al, 2004). Although RDC1 is expressed by a number of cancer cell lines, it does not induce an intracellular calcium-flux or migration but may promote cell survival and adhesion (Burns et al, 2006).

The presentation of chemokines to their receptors in vivo is dependent on the glycosaminoglycan (GAG) components of cell surface or extracellular matrix proteoglycan molecules. Binding occurs between anionic, sulphated GAG residues and basic aminoacid domains within the chemokine primary structure (Ali et al, 
2000). Mutagenesis studies have shown that GAG-binding is necessary before chemokines can stimulate normal cell migration in vivo (Ali et al, 2005; Proudfoot, 2006). It has been proposed that the immobilisation of chemokines by GAGs is required to support the stable, solid-phase chemokine concentration gradients necessary for leukocyte trafficking in vivo (Kuschert et al, 1999). Binding of chemokines to cell surface GAGs may also increase their local concentration (Hoogewerf et al, 1997), resulting in more sensitive signalling by specific chemokine receptors. Heparan sulphate is a polysulphated, highly negatively charged GAG synthesised in the Golgi, and is the predominant GAG present on the apical surface of vascular endothelial cells (Esko and Lindahl, 2001).

It is now thought that the metastasis of breast cancer cells is driven by the presentation of CXCL12 by heparan sulphate on the vascular endothelium and ECM. This induces the activation of integrins on CXCR4-expressing breast cancer cells which causes transendothelial migration of the cells followed by growth and angiogenesis resulting in secondary tumours (Beckmann et al, 1997; Murphy, 2001; Kucia et al, 2004; Luker and Luker, 2006). In vivo studies have confirmed the importance of CXCL12/CXCR4 interactions in breast cancer metastasis. Muller et al (2001) employed antibodies against CXCR4 in a model of breast cancer metastasis over 28 days, which dramatically reduced the incidence of lung metastases by $67 \%$. A number of studies have investigated the knock down of CXCR4 using siRNA in breast cancer models. Liang et al (2005) demonstrated a significant decrease in the number of metastases in SCID mice inoculated with MDA-MB 231 cells transfected with CXCR4 siRNA compared to controls.

It is already known that the binding of chemokine to soluble heparan sulphate or heparin can inhibit the activation of leukocyte-borne chemokine receptors and prevent chemokinedependant lymphocyte adhesion and migration (Kuschert et al, 1999; Ali et al, 2000; Sadir et al, 2001; Hecht et al, 2004). Heparinoids therefore provide a potential approach for inhibiting breast cancer metastasis, although their anticoagulant activity might complicate clinical application.

The current study was designed to determine the minimal chain length of a heparin oligosaccharide that could significantly inhibit CXCL12-mediated breast cancer metastasis, while abrogating the potential anticoagulation problems associated with the use of heparin as an antimetastatic treatment. A series of in vitro experiments were performed to determine the shortest length of oligosaccharide capable of competing CXCL12 from a solid-phase of heparin or heparan sulphate matrix and inhibiting breast cancer cell migration, while exerting little or no anticoagulant effect. Once the minimum length oligosaccharide was determined, in vivo experiments were designed to investigate the antagonistic effects of these oligosaccharides when compared to polymeric heparin on the haematological metastasis of CXCR4 expressing breast cancer cells. A final series of in vitro experiments were performed to define a candidate mechanism for the antimetastatic effect produced by heparinoids in vivo. We determined that a dodecasaccharide, an oligosaccharide composed of 12 monomeric sugar units (dp12) was the shortest length oligosaccharide able to significantly compete for CXCL12 binding against heparan sulphate in vitro. Dodecasaccharides exerted less anticoagulation activity than either polymeric heparin or the low molecular weight heparin Tinzaparin. Heparin significantly inhibited the formation of lung metastases in vivo. However, dp12 did not reduce the number of lung metastases, but did reduce the area of individual lesions.

\section{MATERIALS AND METHODS}

\section{Preparation of oligosaccharides}

Three $2 \mathrm{ml}$ vials of the low molecular weight heparin product Tinzaparin (Leo Pharmaceuticals, Princes Risborough, UK), were pooled and applied to two Bio-Gel P10 columns $(3 \times 120 \mathrm{~cm}$; Bio-Rad, Hamel Hempstead, UK) linked in series and eluted with $0.25 \mathrm{M} \mathrm{NH}_{4} \mathrm{HCO}_{3}$ at a flow rate of $9 \mathrm{ml} \mathrm{h}^{-1}$. Tinzaparin is produced through the enzymatic degradation of polymeric heparin using the enzyme heparinase I (Linhardt and Gunay, 1999). Fractions of $3 \mathrm{ml}$ were collected; their absorbance at $232 \mathrm{~nm}$ measured and relevant fractions pooled. After lyophilisation, the samples were dissolved at a concentration of $100 \mu \mathrm{g}^{-1}$ before precipitation with three volumes of ice-cold ethanol containing $5 \%$ potassium acetate (Sigma, Poole, UK). The samples were centrifuged, the supernatant removed and the pellets left to dry overnight at room temperature before being weighed. This procedure typically yielded around $10 \mathrm{mg}$ of oligosaccharide and was repeated as necessary to obtain sufficient quantities of oligosaccharide material. Fractions pooled to obtain dp24 and dp26 oligosaccharides are approximations as no clear peak corresponding to these size pools was directly detected within the size-exclusion profile of Tinzaparin.

\section{Radioligand binding assays}

Scintillant-coated 96-well plates (Flashplate; PerkinElmer, Waltham, MA, USA) were treated overnight with $200 \mu \mathrm{l}$ of $0.25 \mathrm{mg} \mathrm{ml}^{-1}$. PolyL-lysine hydrobromide (PLL; Sigma) in PBS. Following washing with $0.01 \mathrm{M}$ PBS, the wells were incubated with $250 \mu$ l of heparin (H3400; Sigma) or heparan sulphate (Sigma) at a concentration of $50 \mu \mathrm{g} \mathrm{ml}^{-1}$ in PBS for $2 \mathrm{~h}$ at $37^{\circ} \mathrm{C}$; negative control wells contained only PBS. The wells were then washed twice in binding buffer $(1 \mathrm{mM}$ $\mathrm{CaCl}_{2}, 5 \mathrm{mM}_{\mathrm{MgCl}_{2}}, 0.5 \%$ BSA, $50 \mathrm{~mm}$ HEPES; $\mathrm{pH}$ 7.2). Soluble competitor was added in a volume of $150 \mu \mathrm{l}$ per well at desired concentrations followed by the addition of $5 \mathrm{~nm}$ unlabelled CXCL12 (PeproTech EC LTD, London, UK) with a tracer concentration of $100 \mathrm{pM}{ }^{125} \mathrm{I}-\mathrm{CXCL} 12$ (PerkinElmer) in a volume of $50 \mu \mathrm{l}$ in binding buffer. The plates were incubated at room temperature for $3 \mathrm{~h}$ with shaking and the solution was removed from each well. After washing three times with $200 \mu \mathrm{l}$ of binding buffer the bound radioactivity was measured in a scintillation counter (Microbeta; LKB Wallac, PerkinElmer, Waltham, MA, USA).

\section{Chemotaxis assays}

LMD MDA-MB 231 cells were assayed for their ability to migrate through an $8 \mu \mathrm{m}$ pore diameter filter membrane (Falcon culture inserts; Becton Dickinson, Cowley, UK) towards $12.5 \mathrm{~nm}$ CXCL12. 200000 cells were placed in the upper chamber and the lower chamber was loaded with medium containing $12.5 \mathrm{nM}$ CXCL12 and varying concentrations of dp12. The assay was incubated for $8 \mathrm{~h}$ at $37^{\circ} \mathrm{C}$ before removal of excess cells and medium from both chambers. The upper surface of each filter was gently swabbed before removal and fixation in methanol at $0^{\circ} \mathrm{C}$ for $1 \mathrm{~h}$. The filters were then stained with $0.1 \%$ Mayer's haematoxylin (Sigma) for $10 \mathrm{~min}$, followed by a $10 \mathrm{~min}$ wash in Scott's tap water $(166 \mathrm{~mm}$ $\mathrm{MgSO}_{4}, 24 \mathrm{~mm} \mathrm{NaHCO}$ ). Finally, the filters were sequentially dehydrated with 50, 75, 90 and $100 \%$ ethanol, air-dried and mounted. Migrant cells on each filter were identified by highpower microscopy $(\times 40)$ and counted in nine randomly selected fields; the operator was blinded to the treatments.

\section{Anti-coagulation assay}

The anti-coagulation effects (anti-Xa activity) of heparin $\left(2.2 \mu \mathrm{g} \mathrm{ml}^{-1}\right)$, Tinzaparin $\left(3.4 \mu \mathrm{g} \mathrm{ml}^{-1}\right.$; Leo Pharmaceuticals), and dp12 oligosaccharides $\left(0-34 \mu \mathrm{g} \mathrm{ml}^{-1}\right)$ were examined in plasma. Whole blood mixed with an appropriate heparinoid was added to citrated blood collection tubes and immediately analysed. Briefly, the plasma was centrifuged at $3000 \mathrm{~g}$ for $20 \mathrm{~min}$ and transferred to fresh tubes. The anti-Xa level of each sample was then assessed using the Biophen heparin 6 kit (Hyphen BioMed, Neuville-surOise, France) and the COAG-A-MATE MTX II (BioMerieux, Marcy 
l'Etoile, France) coagulation analyser. Each batch of samples was analysed in conjunction with Biophen low molecular weight heparin (LMWH) control plasma and Biophen heparin control plasma (Hyphen Biomed) as standards.

\section{In vivo metastasis study}

All animal experiments were performed in accordance with local ethical review committee and Home Office Project Licence (PPL 60/3375) approval. All reasonable efforts were made to minimise the suffering likely to be caused and the number of animals to be used. All animals were inspected daily by a qualified technician and weighed twice weekly to ensure thorough assessment of the health of all animals involved.

CB-17 severe combined immunodeficient (SCID) mice (Charles River Labs, Wilmington, MA, USA) were injected subcutaneously with $3.3 \mathrm{mg} \mathrm{kg}^{-1}$ day $^{-1}\left(600 \mathrm{IU} \mathrm{kg}^{-1}\right.$ day $\left.^{-1}\right)$ of heparin in PBS every $12 \mathrm{~h}$, once a day with dp12 in PBS $\left(4.0 \mathrm{mg} \mathrm{kg}^{-1}\right.$ day $\left.^{-1}\right)$ or with PBS alone. Seven mice were treated in each group. Four hours after the first PBS/heparinoid injection, mice were injected with $2 \times 10^{5} \mathrm{LMD}$ MDA-MB 231 breast carcinoma cells into the tail vein. Lungs were collected on day 28 and fixed for histopathology. Twenty sections were cut from each mouse lung at intervals of $50 \mu \mathrm{m}$ in depth.

Lung sections were assessed blindly at $\times 10$ magnification (Leica DMR) and the area of metastasis was calculated using Leica Q-Win software. Both the number and area of the metastatic lesions were assessed blindly by two separate investigators (Paul Mellor and James Harvey).

\section{CXCL12 immunohistochemistry of frozen tissue}

Serial sections ( $5 \mu \mathrm{m}$ thick) of mouse lung were fixed in acetone for $10 \mathrm{~min}$ at room temperature and then air dried. Following a wash for $5 \mathrm{~min}$ in tris-buffered saline (TBS), endogenous peroxidase activity was blocked by incubating for a further $5 \mathrm{~min}$ in $0.6 \% \mathrm{H}_{2} \mathrm{O}_{2}$ in methanol. Sections were then rinsed in distilled water and washed for a further $5 \mathrm{~min}$ in TBS; antigen retrieval was not necessary. Endogenous avidin and biotin were blocked (SP-2001; Vector Labs, Peterborough, UK). Non-specific binding of the secondary antibody was prevented by incubation of the sections with $20 \%$ rabbit's serum in TBS for $1 \mathrm{~h}$ at $4{ }^{\circ} \mathrm{C}$. Sections were then incubated overnight at $4^{\circ} \mathrm{C}$ with primary antibody anti-CXCL12 (Mab310; Sigma) at a concentration of $1 / 20$ in $20 \%$ rabbit's serum/TBS solution. Two control sections per tumour were also incubated in every run of immunohistochemistry; these sections were incubated overnight with no primary antibody (20\% rabbit's serum/TBS alone). Following washing in TBS, sections were incubated for $1 \mathrm{~h}$ at room temperature with a rabbit-anti-mouse biotinylated secondary antibody (1/250; Dako, Ely, UK). After a further wash step in TBS, sections were incubated for $30 \mathrm{~min}$ in the dark with a Streptavidin $\mathrm{ABC}$ complex (Vectastain $\mathrm{ABC}$; Vector Labs) at room temperature. A final wash step was performed before incubation with NiDAB (SK-4100 substrate kit; Vector Labs) for visualisation.

Light counterstaining with Haematoxylin (Sigma) was performed on all specimens before mounting; this enabled visualisation of the tissue architecture without masking of the NiDAB staining. Sections unstained with antibody were dual stained with Haematoxylin and Eosin (H\&E) to demonstrate the tissue architecture in serial sections. Slides were dehydrated through a series of alcohol baths (50, 70, 90, 95 and 100\% alcohol), cleared in xylene and mounted using dibutylphthalate xylene. Sections were compared with controls, where lungs were stained with an isotype control instead of an anti-CXCL12 primary antibody.

\section{CXCR4 real-time RT-PCR}

Total RNA was isolated from murine lung tissue using Trizol (Life Technologies, Paisley, UK) and cDNA was generated using oligo-dT primers with the Superscript II RNase reverse transcription system (Invitrogen, Paisley, UK). Real-time TaqMan PCR was performed according to Applied Biosystems protocols. All samples were loaded in triplicate wells and fluorescence emission detected by the ABI Prism 7000 (Applied Biosystems, Foster City, CA, USA). Primers and probes for CXCR4 were purchased from Applied Biosystems. All results were normalised to the expression of endogenous glyceraldehydes-3-phosphate dehydrogenase mRNA and expressed as a relative increase or decrease in expression compared to PBS controls.

\section{Statistical analysis}

Data values for radioligand binding, chemotaxis assays and in vivo metastasis model were expressed as means \pm s.e.m. Statistical analysis was performed using an unpaired two-tailed Student's $t$-test or using a one-way analysis of variance when multiple data sets are being compared; $P<0.05$ was considered significant.

\section{RESULTS}

Determination of shortest-length oligosaccharide of heparin capable of significantly competing CXCL12 from heparan sulphate

Radioligand binding assays were performed to determine the potential of varying concentrations of soluble heparin and heparin oligosaccharides to compete with polymeric heparin or heparan sulphate to bind ${ }^{125} \mathrm{I}$-CXCL12. Initially, polymeric heparin and the oligosaccharides dp26-dp8 were used at a constant concentration of $7 \mu \mathrm{g} \mathrm{ml}^{-1}$ (representative molar concentrations: dp26-0.9 $\mu \mathrm{M}$, $\mathrm{dp} 8-3 \mu \mathrm{M})$, determined from the $\mathrm{IC}_{50}$ of the dp26 oligosaccharides (results not shown), to compete CXCL12 from a solid phase of heparin. Polymeric heparin and the oligosaccharides dp26-dp16 all competed significantly $(P<0.001$; Figure $1 \mathrm{~A})$ with solid-phase heparin, whereas the competition exerted by dp14 and 12 ( 7 and $5 \%$ respectively) was not significant $(P>0.05)$. As the length of the oligosaccharides decreased so did the level of competition seen. Unexpectedly, the oligosaccharides $\mathrm{dp} 10$ and 8 caused a small increase in binding of CXCL12 to solid-phase heparin.

When analysed over a range of concentrations both the dp14 and 12 oligosaccharides significantly competed with solid-phase heparin at similar low concentrations $\left(12.5 \mu \mathrm{g} \mathrm{ml}^{-1} ; P<0.001\right)$, whereas the dp10 and 8 oligosaccharides were required at much higher concentrations $\left(50 \mu \mathrm{g} \mathrm{ml}^{-1}\right.$ and in excess of $100 \mu \mathrm{g} \mathrm{ml}^{-1}$ respectively) to achieve similar levels of competition (40\% inhibition; Figure 1B). The ability of the dp14, 12 and 10 oligosaccharides to compete CXCL12 from a more biologically relevant solid phase of heparan sulphate was also measured. As with the previous experiment both the dp14 and 12 oligosaccharides significantly competed for CXCL12 at similar low concentrations $\left(1 \mu \mathrm{g} \mathrm{ml}^{-1}\right)$, but higher concentration of the dp10 oligosaccharides were required to exert the same level of competition (Figure 1C).

\section{Assessment of the effects of dp12 on breast cancer cell migration in vitro}

Following definition of $\mathrm{dp} 12$ as the shortest oligosaccharide to significantly bind CXCL12, this size pool was assayed for its effect on breast cancer cells in vitro. It was found that the migration of breast cancer cells across transmembrane filters towards $12.5 \mathrm{nM}$ CXCL12 was significantly inhibited in the presence of $25 \mu \mathrm{g} \mathrm{ml}^{-1}$ $(7 \mu \mathrm{M})$ of the dp12 oligosaccharide $(P<0.001$; Figure 2$)$. In the presence of $100 \mu \mathrm{g} \mathrm{ml}^{-}$of dp12 the number of migrant cells was similar to the background level with no chemokine $(P>0.05)$. 

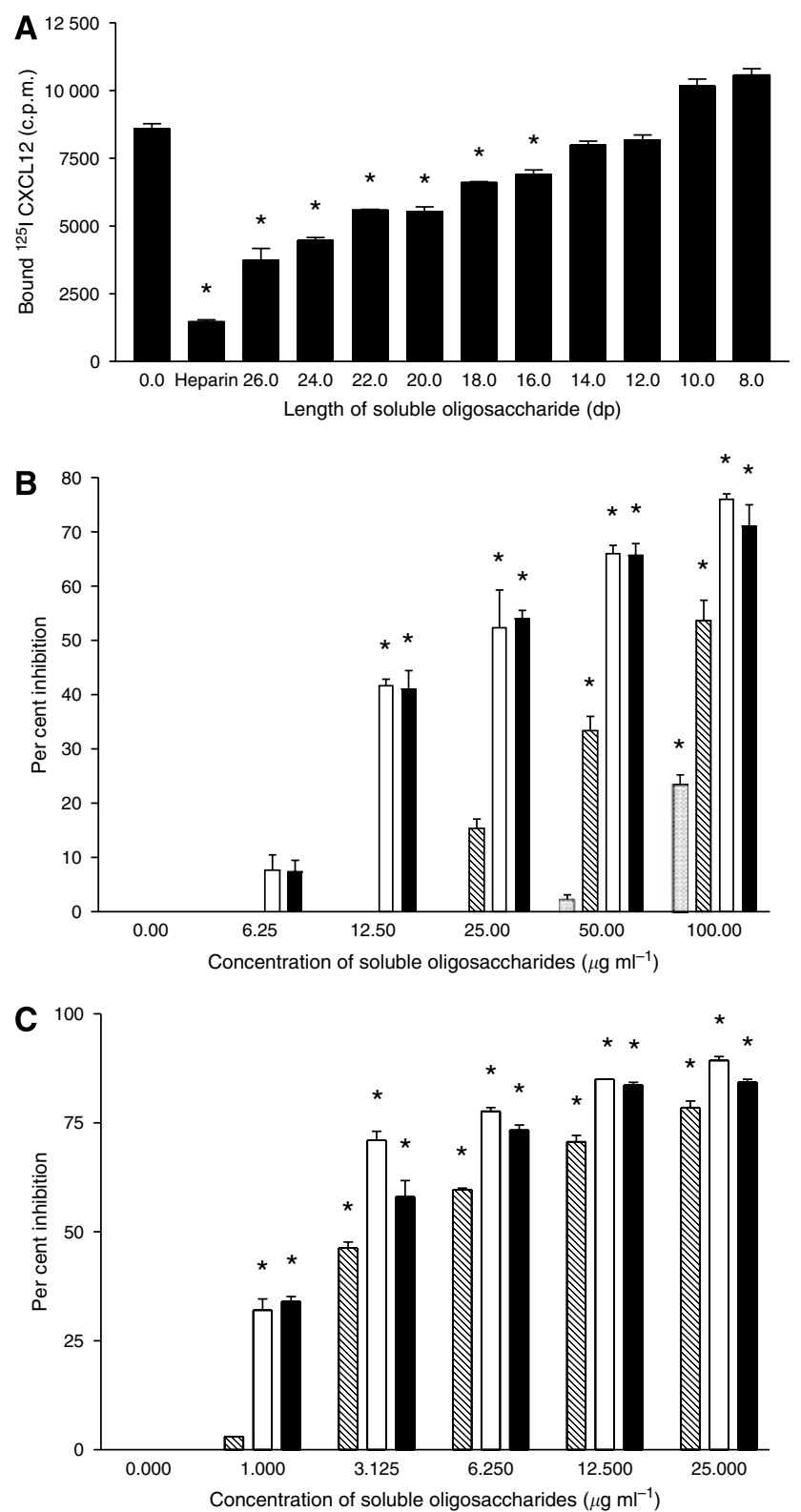

Figure I The shortest length oligosaccharide of heparin capable of significantly competing ${ }^{125} \mathrm{I}-\mathrm{CXCL} / 2$ from solid-phase heparin or heparan sulphate $\left(50 \mu \mathrm{g} \mathrm{ml}^{-1}\right)$ was determined using radioligand competition binding assays. (A) Initially a range of soluble oligosaccharides between 26 and 8 monosaccharide units in length and heparin $\left(7 \mu \mathrm{g} \mathrm{ml}^{-1}\right)$, were assessed with solid-phase heparin $\left(50 \mu \mathrm{g} \mathrm{ml}^{-1}\right)$. The oligosaccharides $\mathrm{dp} / 4$ (filled), dp I 2 (open), dp I0 (hashed) and dp8 (dots) were then (B) used at a range of concentrations to compete CXCLI 2 from heparin. Finally $(\mathbf{C})$ the $\mathrm{dp} / 4, \mathrm{dp} / 2$ and $\mathrm{dp} / 0$ oligosaccharides were competed against a heparan sulphate solid-phase for $\mathrm{CXCLI2}$ binding at a range of concentrations $(* P<0.00 I)$. Data are representative of three individual experiments; bars show mean values \pm s.e.m.

\section{Analysis of the anticoagulant potential of heparinoids}

An important aim of this study was to identify heparin oligosaccharides that possess less anticoagulant activity than the polymeric heparin molecule from which they are derived. To achieve this anti-Xa levels were assessed in plasma isolated from whole blood that had received doses of heparin $\left(2.2 \mu \mathrm{g} \mathrm{ml}^{-1}\right)$, Tinzaparin, a LMWH with a similar average molecular weight to $\mathrm{dp} 12\left(3.4 \mu \mathrm{g} \mathrm{ml}^{-1}\right)$ and $\mathrm{dp} 12\left(3.4 \mu \mathrm{g} \mathrm{ml}^{-1} ; 1 \mu \mathrm{M}\right)$ (Figure $\left.3 \mathrm{~A}\right)$. The

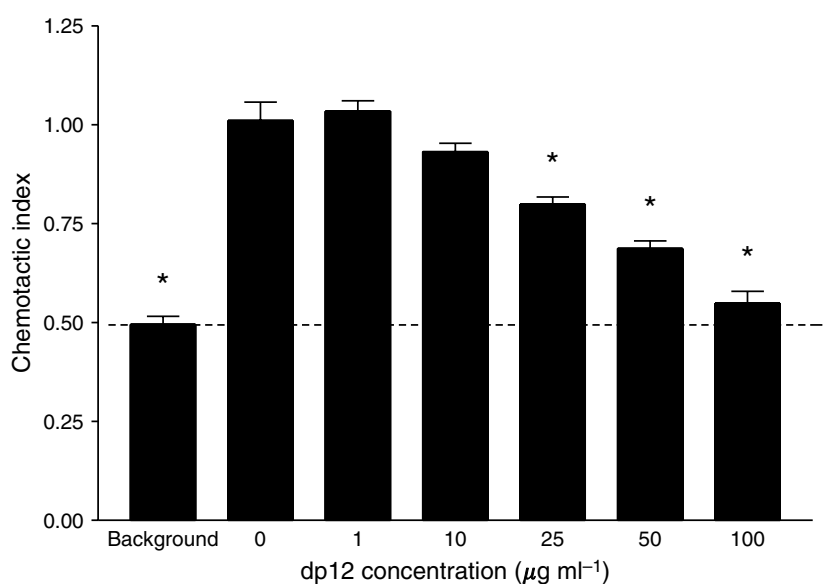

Figure 2 The effects of $d p / 2$ on the migration of breast cancer cells. The number of LMD MDA-MB 23I cells migrating through $8 \mu \mathrm{M}$ pores towards I $2.5 \mathrm{nM} \mathrm{CXCLI} 2$ was measured in the presence of varying concentrations of the $\mathrm{dp} / 2$ inhibitor $(* P<0.00 \mathrm{I})$. The results are expressed as a chemotactic index normalised to the number of migrating cells in the
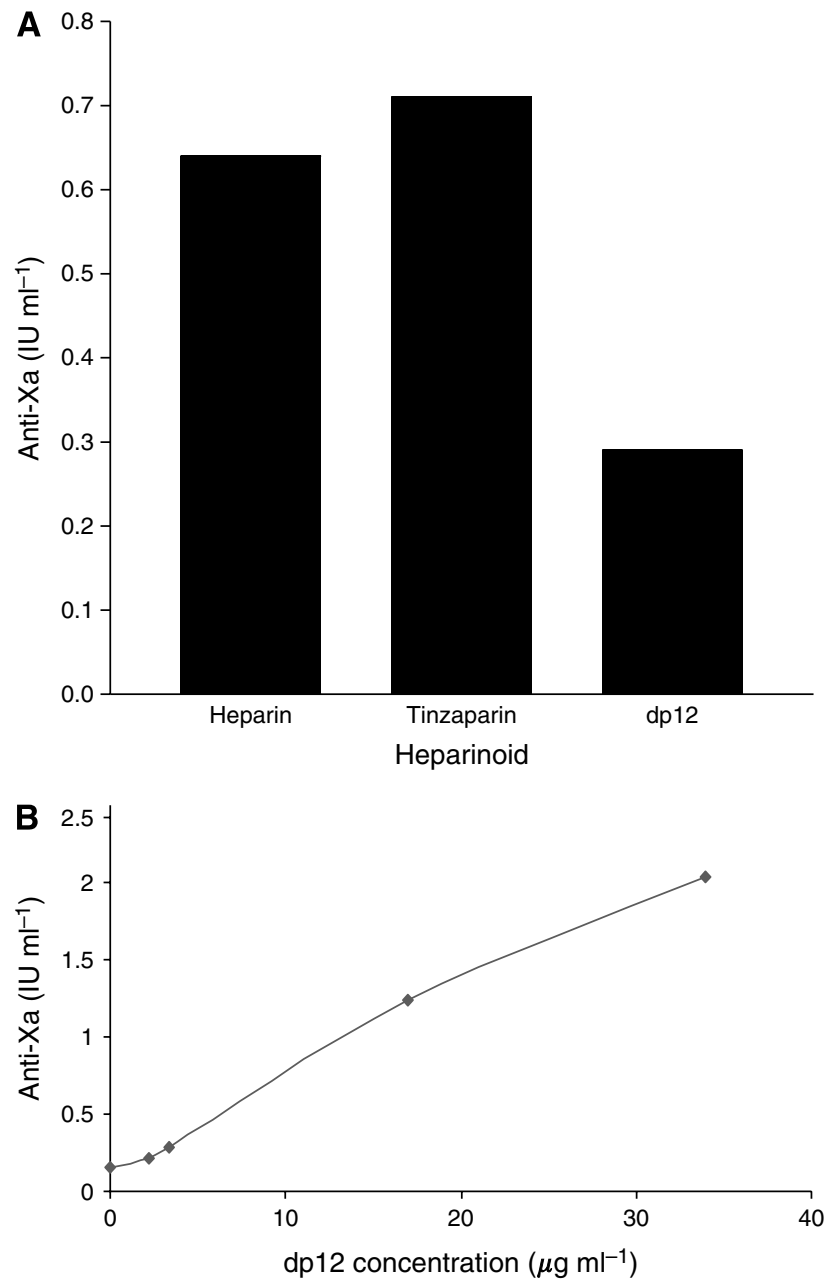

Figure 3 The anticoagulation properties of $\mathrm{dp}$ /2. (A) Anti-Xa levels in plasma isolated from whole blood receiving doses of heparin, tinzaparin and an equivalent dose (weight) of $\mathrm{dp} / 2$; therapeutic levels are between $0.5-1.0$ anti-Xa IU ml ${ }^{-1}$. (B) Anti-Xa levels in whole blood containing varying doses of $\mathrm{dp} / 2$. 
doses of both heparin and Tinzaparin were given to achieve plasma concentrations $\left(0.2-0.4 \mathrm{IU} \mathrm{ml}^{-1}\right)$ that correspond to what is clinically known as a therapeutic dose, with therapeutic anti-Xa levels known to be in the range $0.5-1.0$ anti-Xa IU ml ${ }^{-1}$. As there was no known therapeutic dose of $\mathrm{dp} 12$ the same concentration (weight) as that used for Tinzaparin was used. Both heparin and Tinzaparin-treated blood showed anti-Xa IU ml ${ }^{-1}$ values within the therapeutic range $\left(0.64\right.$ and 0.71 anti-Xa IU ml $\left.{ }^{-1}\right)$ respectively. However, the anti-Xa value for dp12-treated blood was $0.29 \mathrm{IU} \mathrm{ml}^{-1}$, which is below therapeutic values. As the concentration of dp12 increased so did the anti-Xa IU ml ${ }^{-1}$ values, indicating that $\mathrm{dp} 12$ is an effective anticoagulant at high concentrations (Figure 3B).

\section{Determination of the effects of heparin and dp12 on breast cancer metastasis in vivo}

LMD MDA-MB 231 cells $\left(2 \times 10^{5}\right)$ were administered intravenously to three groups of seven SCID mice on day 1 . The mice were independently treated from days 0 to 28 with either subcutaneous doses of heparin $\left(3.3 \mathrm{mg}\right.$ or $0.17 \mu \mathrm{mol} \mathrm{kg}^{-1} \mathrm{day}^{-1}$; $600 \mathrm{IU} \mathrm{kg}^{-1} \mathrm{day}^{-1}$ ) given twice daily, $0.1 \mathrm{ml}$ PBS given once daily, or dp12 (4.0 mg or $\left.1.2 \mu \mathrm{mol} \mathrm{kg}^{-1} \mathrm{day}^{-1}\right)$ also given once daily. This dose of heparin is known to produce therapeutic anticoagulation in a clinical setting. Treatment of SCID mice with a single daily dose of Tinzaparin at $175 \mathrm{IU} \mathrm{kg}^{-1} \mathrm{day}^{-1} \quad(1.8 \mathrm{mg}$ or $0.6 \mu \mathrm{mol} \mathrm{kg}^{-1} \mathrm{day}^{-1}$ ) produces a level of anticoagulation, which is just within the therapeutic range $\left(0.51\right.$ anti-Xa IU ml $\left.{ }^{-1}\right)$; data not shown. Given that Tinzaparin has an anticoagulant activity, which is approximately 2.5 times greater than that of dp12, a subanticoagulant dose of $\mathrm{dp} 12$ was chosen to dissociate anticoagulant activity from any putative anticancer effect. The half-life of LMWHs is two to four times that of unfractionated heparin; for this reason, typical clinical regimes involve administration of LMWHs once a day and heparin twice a day (Hirsh and Levine, 1992; Wu, 2001). As both dp12 and LMWHs are the result of polymeric heparin degradation, dp12 was also administered once a day.
A total of 20 sections from each mouse lung were assessed for both the presence and the area of each metastatic lesion (Figure 4). Dp12 had no effect upon the number of breast cancer metastases found in the lungs when compared to control PBS-treated mice (Figure 5A). However, the metastases within the lungs of dp12 treated mice were on average $41 \%$ smaller $(P<0.05)$ than those found in the PBS control mice (Figure 5B). Heparin decreased the number of metastases by $87 \%(P<0.0001)$ compared to the PBStreated group (Figure 5A). No significant difference was identified between the area of metastases in the heparin and the PBS-treated groups (Figure 5B). Only three metastases were identified in the heparin-treated animals $(n=7)$, therefore giving a large s.e.m. for the average size of the lesions identified.

\section{Assessment of the expression of CXCL12 on the lung vascular endothelium and of CXCR4 on the formed metastases}

Both the expression of CXCR 4 on cancer cells and CXCL12 on the apical surface of vascular endothelium were examined to assess the role played by chemokines in the anticancer activity of heparinoids. The surface of normal lung endothelium expressed a high level of CXCL12, which was not altered in PBS-treated control animals (Figure 6A). Treatment with dp12 slightly decreased CXCL12 expression while none of this chemokine was detected on lung endothelium from heparin-treated mice (Figure 6A). Tumours in both the heparin and dp12-treated mice showed a small, but non-significant $(P>0.05)$, decrease in the expression of CXCR4 mRNA in comparison with PBS-treated animals (Figure 6B).

\section{DISCUSSION}

The metastasis of breast cancer cells to specific sites in the body is the main cause of death for patients with this disease (Walker et al, 1997). Recent evidence has shown that this metastasis is mediated through specific cell migration stimulated by the interactions of
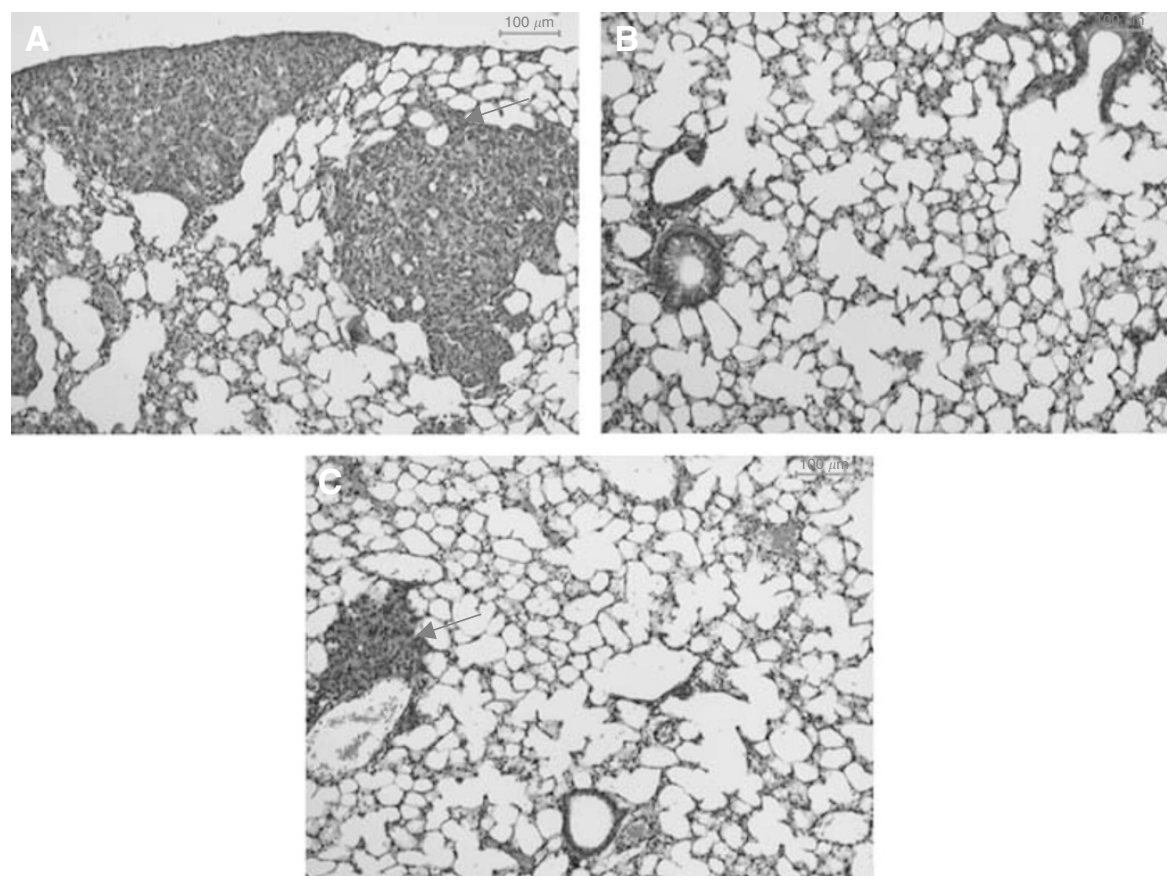

Figure 4 Representative haemotoxylin and eosin staining of tumours (arrows) in animals treated with (A) PBS, (B) heparin and (C) dp I2 for 28 days after intravenous administration of LMD MDA-MB 23I cells. 

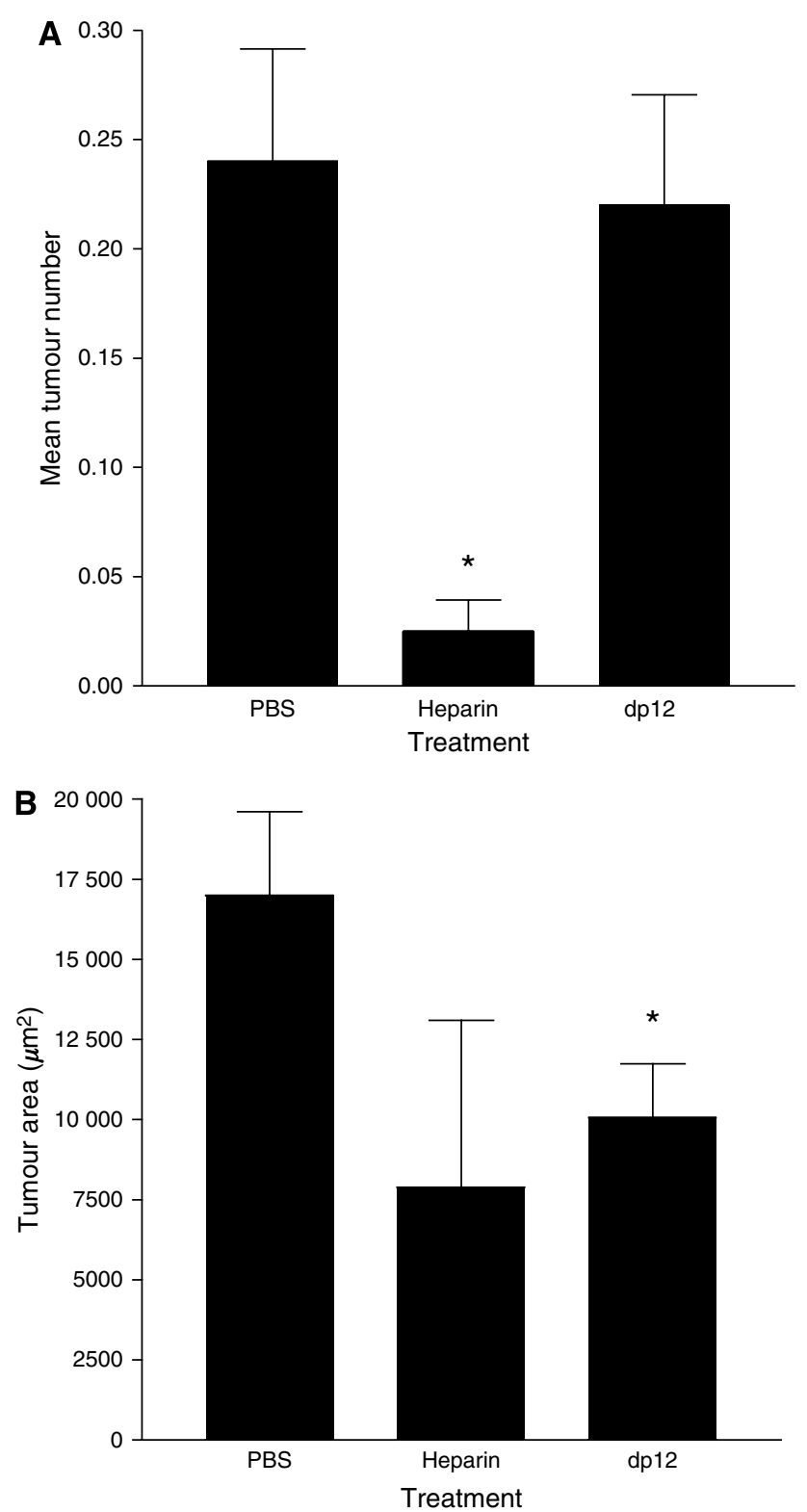

Figure 5 Murine breast cancer model. Following administration of LMD MDA-MB 23I cells, three groups of seven mice were treated for 28 days with subcutaneous doses either of heparin $\left(3.3 \mathrm{mg} \mathrm{kg}^{-1}\right.$ per day) given twice daily, $0.1 \mathrm{ml}$ PBS given once daily, or $\mathrm{dp} / 2\left(4.0 \mathrm{mg} \mathrm{kg}^{-1}\right.$ per day) also given once daily. A total of 20 sections from each mouse lung were $H \& E$ stained and assessed blindly using Leica $Q$ win software for both the number $(\mathbf{A})$ of metastases and the area $(\mathbf{B})$ of each metastasis identified $(* P<0.00 \mathrm{I})$; bars show mean values \pm s.e.m.

CXCL12, presented by heparan sulphate on the vascular endothelium of organs commonly associated with breast cancer metastasis, with CXCR4, expressed at high levels on metastatic breast cancer cells (Muller et al, 2001). Previous studies have shown that heparin is capable of antagonising chemokine function both in vitro and in vivo (Castelli et al, 2004) indicating its potential to disrupt the interaction between CXCL12 and CXCR4, thereby preventing the invasion of CXCR4 expressing breast cancer cells (Dowsland et al, 2003). Clearly, the anticoagulant properties of heparin might limit the usefulness of this molecule in treating breast cancer patients, especially peri-operatively. This study has identified a short-chain length oligosaccharide derived from polymeric heparin capable of inhibiting the migration of breast cancer cells in vitro and limiting the growth of secondary tumours in vivo, while minimising potential anticoagulation problems associated with heparin.

The potential of defined-length heparin oligosaccharides to compete with solid-phase heparin to bind CXCL12 was found to decrease as the chain length decreased. Soluble heparin and the oligosaccharides ranging from dp26 down to 16 in length all competed significantly with solid-phase heparin, while oligosaccharides below 16 monomeric sugar units in length failed to compete. In all cases, a similar amount $\left(7 \mu \mathrm{g} \mathrm{ml}^{-1}\right)$ of definedlength GAG was used to compete with heparin for chemokine binding, suggesting that oligosaccharides containing 14 or fewer monosaccharide units have a reduced potential to bind CXCL12. However, heparinoids below dp14 did show some potential to bind CXCL12 when present at greatly increased concentrations. The most likely explanation for this observation is a reduction in the number of the chemokine binding domains as the chain length of the heparinoid molecule is reduced.

CXCL12 exists as a monomer in solution but forms dimers when interacting with heparin or heparan sulphate (Veldkamp et al, 2005). The stoichiometry of the binding of CXCL12 to GAGs suggests that each chemokine occupies an average of six monosaccharide units on heparin (Altundag et al, 2005). However, Sadir et al (2001) have shown that 13 monosaccharide units are required for interaction with the dimeric form of CXCL12. This is consistent with data in the current study and potentially explains the greater degree of competition seen with dp14 and 12 than with $\mathrm{dp} 10$ and 8 as the longer species are capable of binding dimeric CXCL12, whereas the shorter can only bind monomeric CXCL12. For these reasons, dp12 was chosen for further study.

Cell surface GAGs play important roles in the presentation of chemokines to their specific receptors; these include protection of chemokine molecules from degradation and the maintenance of the stable concentration gradients through the tissues which are required for vectorial cell migration (Perrimon and Bernfield, 2000). However, soluble GAGs have also been demonstrated to antagonise the biological activity of chemokines (Douglas et al, 1997) potentially by production of chemokine-GAG complexes which cannot engage specific chemokine receptors (Ali et al, 2000). The current study confirmed these observations by demonstration that dp12 inhibits the migration of breast cancer cells towards CXCL12 in vitro.

The dp12 oligosaccharide had significantly less anticoagulant activity than either heparin or Tinzaparin. As a consequence, higher doses of dp12 were required to produce a similar level of anti-Xa activity in blood. This can be explained in terms of the relative length of the molecules. It is known that specific pentasaccharide sequences are required for AT binding; these motifs are present in about a third of heparin molecules (Lindahl et al, 1979). However, only between 15 and $25 \%$ of the shorter fragments present in LMWH contain this sequence (Lindahl et al, 1979; Lane et al, 1984; Hirsh, 1998; Herault et al, 2002). The variation in the occurrence of the pentasaccharide between LMWHs results in differences in their ability to bind AT and therefore in inhibiting factor Xa (Nader et al, 2001). The cleavage of heparin required to produce oligosaccharides is likely to disrupt many of these sequence motifs, reducing the number available for AT binding within a given weight of the processed material. Importantly, however, the oligosaccharides retained their potential to antagonise chemokine activity; this is consistent with previous data from our group of the separation of anticoagulant and chemokine-binding functions.

An in vivo breast cancer model was used to determine the ability of heparin to prevent the metastasis of human breast cancer cells from peripheral blood to the lung tissue of SCID mice; importantly, heparin powerfully reduced the number of metastatic lesions observed in the lung while treatment with the dp12 oligosaccharides had no effect on the number of lesions. Further 
A

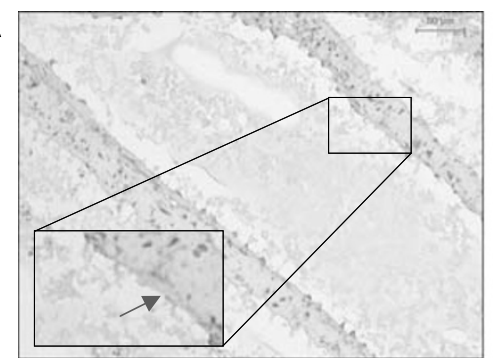

Negative

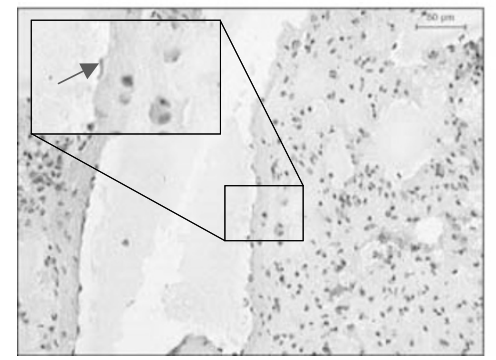

Heparin

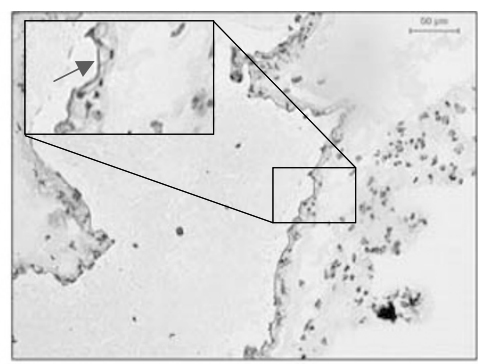

PBS

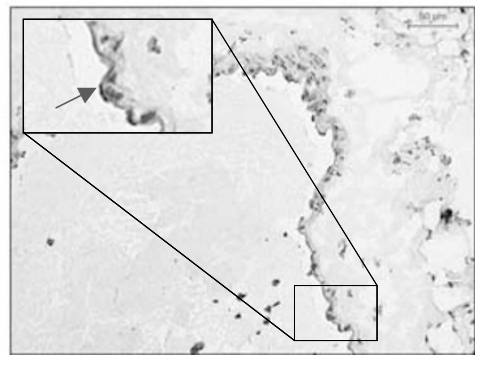

dp12
B

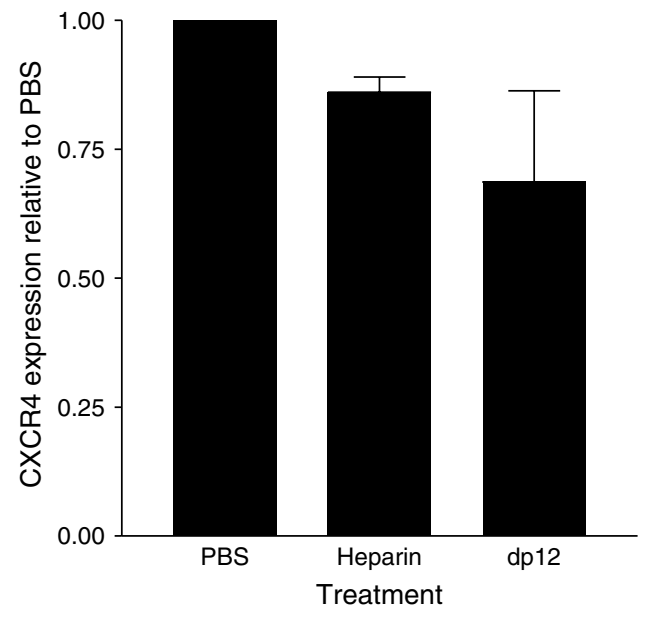

Figure 6 CXCLI2 and CXCR4 expression in mouse lung and tumours. CXCLI2 expression on the surface of the vascular endothelium was assessed by immunohistochemical staining using a CXCLI 2 mouse monoclonal antibody (A) in mouse lung treated with PBS, heparin and dp I 2 for 28 days following administration of LMD MDA-MB 23 I cells (arrows); negative section is isotype control. There was strong CXCLI 2 staining on the vascular endothelium in the PBS-treated group, which was unaltered in the $\mathrm{dp} I 2$ group, whereas CXCLI 2 was absent from the vascular endothelium of the heparin-treated mice. The levels of human CXCR4 expression (B), relative to PBS group, in tumours present in the mouse lung treated with heparin and dp 12 for 28 days following administration of LMD MDA-MB 23 I cells were assessed using real-time PCR normalised to human GAPDH. Data are representative of three individual experiments; bars show mean values \pm s.e.m.

experiments were performed to investigate the possible role of chemokine antagonism in this model. Specifically, it was found that treatment with heparin significantly reduced the expression of CXCL12 on the endothelial and epithelial surfaces in the lung, while dp12 only produced a small decrease in CXCL12 expression. This suggests that heparin therapy reduces the potential of CXCL12 to 'capture' cancer cells within breast tissues. However, no reduction in the ratio between mRNA sequences encoding human CXCR4 and GAPDH was observed in any treatment group suggesting that the absence of immobilised CXCL12 in heparintreated animals did not select for non-CXCR4-expressing variants of the cancer.

The tumours in the dp12-treated group were significantly smaller in size than those in the PBS-treated control group. Tumour growth is dependent not only on growth factors produced by the cancer cells themselves but also those present in the surrounding microenvironment. Heparinoids are very anionic molecules that can bind and modulate the function of a wide range of cytokines and adhesion molecules (Dowsland et al, 2003), inducing numerous changes in the tissue microenvironment with the potential to affect cancer cell growth. It is therefore most probable that dp12 is affecting factors other than CXCL12 in mediating its effects on tumour growth. For example, heparin derivatives as short as eight monosaccharide units can bind both FGF-2 and VEGF in vivo (Ishihara et al, 1993; Tyrrell et al, 1993; Hurwitz et al, 2004); this prevents these growth factors from binding to heparan sulphate leading to inhibition of angiogenesis (Hasan et al, 2005). As these oligosaccharides prevent FGF-2 and VEGF from binding to heparan sulphate, they function as antagonists of angiogenesis and have been shown in vivo to inhibit the development of new vasculature (Hasan et al, 2005).

However, it is important to stress that the action of heparin in inhibiting breast cancer metastasis is potentially multifactorial, and not solely the result of the inhibition of CXCL12/heparan sulphate interactions. Studies examining the role of soluble heparin in breast cancer have demonstrated a number of mechanisms vital for breast cancer metastasis that can be disrupted by heparin. These include the inhibition of the adhesion and migration of breast cancer cells by heparin-mediated inhibition of selectin binding and proteases These processes are influenced to a greater degree by heparin than LMWHs and may potentially explain the differences seen between heparin and dp12 (Vlodavsky et al, 1994; Koenig et al, 1998; Borsig, 2004). In addition, if dp12 does function by inhibiting the action of growth factors on the breast cancer cells it is unlikely that heparin will be functioning in a similar manner with studies demonstrating a promotional role for heparin in the presentation of growth factor receptors, in contrast to shorter length oligosaccharides (Soker et al, 1994; Norrby and Ostergaard, 1996).

In conclusion, these data show that relatively non-anticoagulant concentrations of a soluble dp12 oligosaccharide can significantly inhibit the migration of breast cancer cells in vitro, but only inhibit the growth and not the number of lung metastases which form in vivo. However, anticoagulant concentrations of heparin can significantly inhibit both in vitro migration and the metastatic spread of breast cancer cells in vivo. As viable cancer cells are liberated into the vasculature during surgical resection, heparin may offer a potential antimetastatic therapy. Although clinically dp12 would not be applicable as an antimetastatic therapy it may prove useful in inhibiting the growth of established tumours, offering a potential treatment following diagnosis and before surgery. The oligosaccharide may also prove beneficial to patients with non-operable tumours by extending survival times.

\section{ACKNOWLEDGEMENTS}

We are grateful to the Newcastle Royal Victoria Infirmary Breast Cancer Appeal for financial support. 


\section{REFERENCES}

Ali S, Palmer AC, Banerjee B, Fritchley SJ, Kirby JA (2000) Examination of the function of RANTES, MIP-1alpha, and MIP-1beta following interaction with heparin-like glycosaminoglycans. J Biol Chem 275: 11721 - 11727

Ali S, Robertson H, Wain JH, Isaacs JD, Malik G, Kirby JA (2005) A nonglycosaminoglycan-binding variant of CC chemokine ligand 7 (monocyte chemoattractant protein-3) antagonizes chemokine-mediated inflammation. J Immunol 175: $1257-1266$

Altundag K, Altundag O, Atik MA (2005) Heparin and CXCL12 dimerization. J Clin Oncol 23: 7248

Amara A, Lorthioir O, Valenzuela A, Magerus A, Thelen M, Montes M, Virelizier JL, Delepierre M, Baleux F, Lortat-Jacob H, Arenzana-Seisdedos F (1999) Stromal cell-derived factor-1alpha associates with heparan sulfates through the first beta-strand of the chemokine. J Biol Chem 274: 23916-23925

Azenshtein E, Luboshits G, Shina S, Neumark E, Shahbazian D, Weil M, Wigler N, Keydar I, Ben-Baruch A (2002) The CC chemokine RANTES in breast carcinoma progression: regulation of expression and potential mechanisms of promalignant activity. Cancer Res 62: 1093-1102

Balabanian K, Lagane B, Infantino S, Chow KY, Harriague J, Moepps B, Arenzana-Seisdedos F, Thelen M, Bachelerie F (2005) The chemokine SDF-1/CXCL12 binds to and signals through the orphan receptor RDC1 in T lymphocytes. J Biol Chem 280: 35760-35766

Beckmann MW, Niederacher D, Schnurch HG, Gusterson BA, Bender HG (1997) Multistep carcinogenesis of breast cancer and tumour heterogeneity. J Mol Med 75: 429-439

Borsig L (2004) Selectins facilitate carcinoma metastasis and heparin can prevent them. News Physiol Sci 19: 16-21

Burns JM, Summers BC, Wang Y, Melikian A, Berahovich R, Miao Z, Penfold ME, Sunshine MJ, Littman DR, Kuo CJ, Wei K, McMaster BE, Wright K, Howard MC, Schall TJ (2006) A novel chemokine receptor for SDF-1 and I-TAC involved in cell survival, cell adhesion, and tumor development. J Exp Med 203: 2201 - 2213

Castelli R, Porro F, Tarsia P (2004) The heparins and cancer: review of clinical trials and biological properties. Vasc Med 9: 205-213

Chen GS, Yu HS, Lan CC, Chow KC, Lin TY, Kok LF, Lu MP, Liu CH, Wu MT (2006) CXC chemokine receptor CXCR4 expression enhances tumorigenesis and angiogenesis of basal cell carcinoma. Br J Dermatol 154: 910-918

Douglas MS, Ali S, Rix DA, Zhang JG, Kirby JA (1997) Endothelial production of MCP-1: modulation by heparin and consequences for mononuclear cell activation. Immunology 92: 512-518

Dowsland MH, Harvey JR, Lennard TW, Kirby JA, Ali S (2003) Chemokines and breast cancer: a gateway to revolutionary targeted cancer treatments? Curr Med Chem 10: 579-592

Esko JD, Lindahl U (2001) Molecular diversity of heparan sulfate. J Clin Invest 108: $169-173$

Fernandis AZ, Prasad A, Band H, Klosel R, Ganju RK (2004) Regulation of CXCR4-mediated chemotaxis and chemoinvasion of breast cancer cells. Oncogene 23: $157-167$

Hasan J, Shnyder SD, Clamp AR, McGown AT, Bicknell R, Presta M, Bibby M, Double J, Craig S, Leeming D, Stevenson K, Gallagher JT, Jayson GC (2005) Heparin octasaccharides inhibit angiogenesis in vivo. Clin Cancer Res 11: $8172-8179$

Hecht I, Hershkoviz R, Shivtiel S, Lapidot T, Cohen IR, Lider O, Cahalon L (2004) Heparin-disaccharide affects T cells: inhibition of NF-kappaB activation, cell migration, and modulation of intracellular signaling. J Leukoc Biol 75: 1139-1146

Herault JP, Bernat A, Roye F, Michaux C, Schaeffer P, Bono F, Petitou M, Herbert JM (2002) Pharmacokinetics of new synthetic heparin mimetics. Thromb Haemost 87: 985-989

Hirsh J, Levine MN (1992) Low molecular weight heparin. Blood 79: 1-17

Hirsh J (1998) Low-molecular-weight heparin: A review of the results of recent studies of the treatment of venous thromboembolism and unstable angina. Circulation 98: $1575-1582$

Hoogewerf AJ, Kuschert GS, Proudfoot AE, Borlat F, Clark-Lewis I, Power CA, Wells TN (1997) Glycosaminoglycans mediate cell surface oligomerization of chemokines. Biochemistry 36: $13570-13578$

Hurwitz H, Fehrenbacher L, Novotny W, Cartwright T, Hainsworth J, Heim W, Berlin J, Baron A, Griffing S, Holmgren E, Ferrara N, Fyfe G, Rogers B, Ross R, Kabbinavar F (2004) Bevacizumab plus irinotecan, fluorouracil, and leucovorin for metastatic colorectal cancer. N Engl J Med 350: 2335-2342

Ishihara M, Tyrrell DJ, Stauber GB, Brown S, Cousens LS, Stack RJ (1993) Preparation of affinity-fractionated, heparin-derived oligosaccharides and their effects on selected biological activities mediated by basic fibroblast growth factor. J Biol Chem 268: $4675-4683$
Koenig A, Norgard-Sumnicht K, Linhardt R, Varki A (1998) Differential interactions of heparin and heparan sulfate glycosaminoglycans with the selectins. Implications for the use of unfractionated and low molecular weight heparins as therapeutic agents. J Clin Invest 101: 877-889

Kucia M, Jankowski K, Reca R, Wysoczynski M, Bandura L, Allendorf DJ, Zhang J, Ratajczak J, Ratajczak MZ (2004) CXCR4-SDF-1 signalling, locomotion, chemotaxis and adhesion. J Mol Histol 35: 233-245

Kuschert GS, Coulin F, Power CA, Proudfoot AE, Hubbard RE, Hoogewerf AJ, Wells TN (1999) Glycosaminoglycans interact selectively with chemokines and modulate receptor binding and cellular responses. Biochemistry 38: $12959-12968$

Lane DA, Denton J, Flynn AM, Thunberg L, Lindahl U (1984) Anticoagulant activities of heparin oligosaccharides and their neutralization by platelet factor 4. Biochem J 218: 725-732

Liang Z, Yoon Y, Votaw J, Goodman MM, Williams L, Shim H (2005) Silencing of CXCR4 blocks breast cancer metastasis. Cancer Res 65: 967-971

Lindahl U, Backstrom G, Hook M, Thunberg L, Fransson LA, Linker A (1979) Structure of the antithrombin-binding site in heparin. Proc Natl Acad Sci USA 76: $3198-3202$

Linhardt RJ, Gunay NS (1999) Production and chemical processing of low molecular weight heparins. Semin Thromb Hemost 25(Suppl 3): $5-16$

Luker KE, Luker GD (2006) Functions of CXCL12 and CXCR4 in breast cancer. Cancer Lett 238: 30-41

Moore MA (2001) The role of chemoattraction in cancer metastases. Bioessays 23: 674-676

Moser B, Wolf M, Walz A, Loetscher P (2004) Chemokines: multiple levels of leukocyte migration control. Trends Immunol 25: 75-84

Muller A, Homey B, Soto H, Ge N, Catron D, Buchanan ME, McClanahan T, Murphy E, Yuan W, Wagner SN, Barrera JL, Mohar A, Verastegui E, Zlotnik A (2001) Involvement of chemokine receptors in breast cancer metastasis. Nature 410: $50-56$

Murphy PM (2001) Chemokines and the molecular basis of cancer metastasis. $N$ Engl J Med 345: $833-835$

Nader HB, Pinhal MA, Bau EC, Castro RA, Medeiros GF, Chavante SF, Leite EL, Trindade ES, Shinjo SK, Rocha HA, Tersariol IL, Mendes A, Dietrich CP (2001) Development of new heparin-like compounds and other antithrombotic drugs and their interaction with vascular endothelial cells. Braz J Med Biol Res 34: 699-709

Norrby K, Ostergaard P (1996) Basic-fibroblast-growth-factor-mediated de novo angiogenesis is more effectively suppressed by low-molecular-weight than by high-molecular-weight heparin. Int J Microcirc Clin Exp 16: 8-15

Perrimon N, Bernfield M (2000) Specificities of heparan sulphate proteoglycans in developmental processes. Nature 404: 725-728

Proudfoot AE (2006) The biological relevance of chemokine-proteoglycan interactions. Biochem Soc Trans 34: $422-426$

Sadir R, Baleux F, Grosdidier A, Imberty A, Lortat-Jacob H (2001) Characterization of the stromal cell-derived factor-1alpha-heparin complex. J Biol Chem 276: 8288-8296

Soker S, Goldstaub D, Svahn CM, Vlodavsky I, Levi BZ, Neufeld G (1994) Variations in the size and sulfation of heparin modulate the effect of heparin on the binding of VEGF165 to its receptors. Biochem Biophys Res Commun 203: $1339-1347$

Tyrrell DJ, Ishihara M, Rao N, Horne A, Kiefer MC, Stauber GB, Lam LH, Stack RJ (1993) Structure and biological activities of a heparin-derived hexasaccharide with high affinity for basic fibroblast growth factor. J Biol Chem 268: $4684-4689$

Veldkamp CT, Peterson FC, Pelzek AJ, Volkman BF (2005) The monomerdimer equilibrium of stromal cell-derived factor-1 (CXCL 12) is altered by $\mathrm{pH}$, phosphate, sulfate, and heparin. Protein Sci 14: 1071-1081

Vlodavsky I, Mohsen M, Lider O, Svahn CM, Ekre HP, Vigoda M, IshaiMichaeli R, Peretz T (1994) Inhibition of tumor metastasis by heparanase inhibiting species of heparin. Invasion Metastasis 14: 290-302

Walker RA, Jones JL, Chappell S, Walsh T, Shaw JA (1997) Molecular pathology of breast cancer and its application to clinical management. Cancer Metastasis Rev 16: 5-27

Woodhouse EC, Chuaqui RF, Liotta LA (1997) General mechanisms of metastasis. Cancer 80: $1529-1537$

Wu CL (2001) Regional anesthesia and anticoagulation. J Clin Anesth 13: 49-58

Zlotnik A, Yoshie O (2000) Chemokines: a new classification system and their role in immunity. Immunity 12: 121-127

Zlotnik A (2006) Involvement of chemokine receptors in organ-specific metastasis. Contrib Microbiol 13: $191-199$ 